ATIANTA

Paper ID \#6060

\title{
Proximity of Equations, Text, and Figures in Civil Engineering E-Textbooks
}

Prof. Paul Richards, Brigham Young University 


\section{Proximity of Equations, Text, and Figures in Civil Engineering E-Textbooks}

\section{Introduction}

The increasing cost of higher education in the United States is a pressing political and social issue. Since 1978, higher education tuition and fees have grown 1,120 percent, four times more than the consumer price index (Jamrisko and Kolet, 2012), and at a significantly higher rate than incomes. These cost increases have been supported by increased student loans that bridge the gap between typical incomes and education costs. Student loan debt stood at $\$ 956$ billion as of September 2012, greater than the nation's credit card debt (FRBNY, 2012). This cost-increaseloan-increase cycle for higher education appears unsustainable, particularly in light of stagnant or decreased earning potential of college graduates (Mishel et al., 2012). Default rates on student loans have risen dramatically in recent years and the percentage of student loans that are delinquent now exceeds those for mortgages, credit cards, and auto loans (FRBNY, 2012).

Textbook costs are a contributing factor to this financial problem, particularly in engineering. The average university student spends more than $\$ 900$ each year on textbooks with many paying for books with student loans (GAO, 2005). Textbook prices nearly tripled from 1986 to 2004(GAO, 2005) and have increased at a similar rate in recent years. Textbooks costs are greater-than-average for engineering students; in the Civil Engineering Department at Brigham Young University, students spend between \$1200 and \$2000 each year on textbooks.

Some institutions and governments are mandating e-textbooks in the belief that they will result in cost savings to students. E-textbooks are cheaper to distribute than printed books and can more easily be purchased in bulk by institutions at negotiated prices. One model is for institutions to require all students to pay a course-materials fee; with that money the institutions would obtain e-textbooks from publishers, at bulk rates, and make them available to all their students (Young, 2010). Some larger institutions are looking to bypass traditional publishers altogether. In September 2012 California passed legislation for the state to fund the development of fifty opensource digital textbooks which will be produced by California's universities (Garber, 2012). In January 2012 the Obama administration asked K-12 schools to accelerate the transition to digital textbooks, with the goal of having an e-textbook in every student's hand by 2017. The justification for the push is that it will result in cost savings, more current course content, and a more interactive learning environment for students (Toppo, 2012).

How will these developments in e-textbooks impact engineering education at the university level? Publishers have been quick to offer digital forms of their printed engineering textbooks either in PDF or flowable text formats. These current-generation engineering e-textbooks have the advantages of portability and searchability, but when they are priced the same as the print editions, students generally do not prefer them (Woody et al., 2010). With the increasing use of 
e-textbooks in K-12 and general education settings, and with the exploding ownership of notepad sized e-readers, there may be increasing use of engineering e-textbooks in coming years, especially if their use is mandated by administrators.

As current-generation engineering e-textbooks come into greater use, there are issues that should be appreciated and addressed. This paper explores the loss of proximity, which is an obstacle that should be recognized and addressed in engineering e-textbooks.

Integration of Text, Figures, and Equations in Printed Books

Engineering textbooks typically include text, figures, and equations that are used in combination to communicate ideas. This tradition is centuries old, but in the past century we have deviated from the most effective application. Leonardo da Vinci was a master at using figures to communicate ideas (Figure 1). Tufte notes that “page after page of Leonardo's manuscripts have a gentle but thorough integration of text and figure, a quality rarely seen in modern work" (Tufte, 1983). In modern printed engineering works, graphics are more segregated from the text moved to the top or bottom of the page or into the margins. This separation is driven by the work-flow of modern publishing.

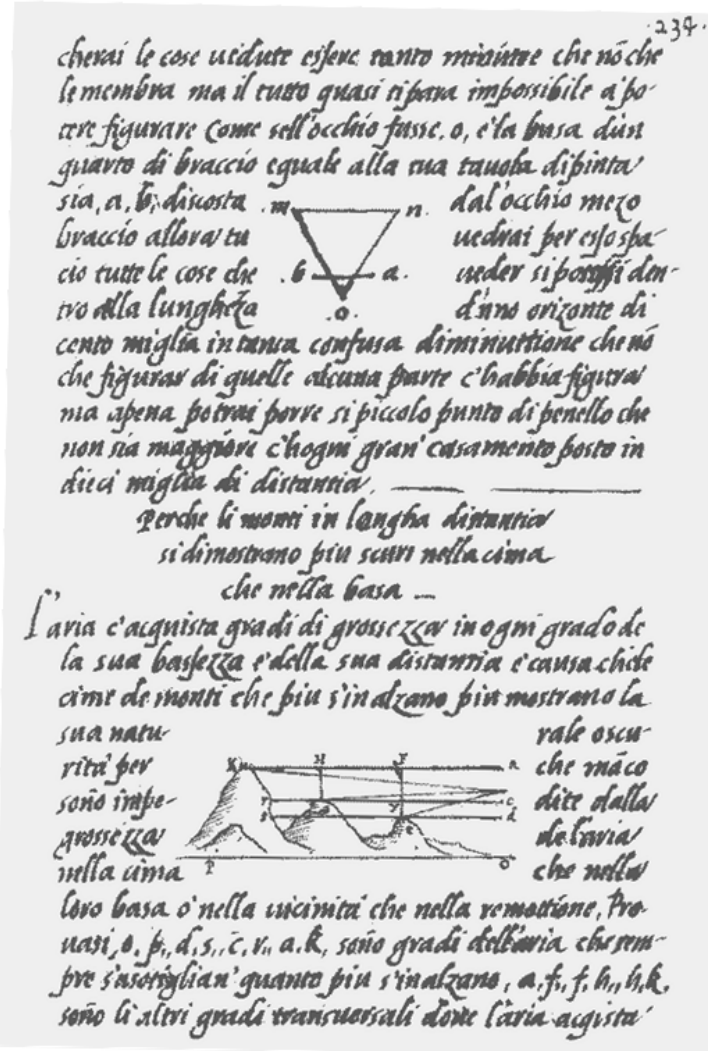

Figure 1 Integration of text and figures in Leonardo da Vinci's work 
Biderman believes that the segregation of text and figures in modern publishing negatively impacts the intellectual quality: "the evolution of graphical methods as an element of the scientific enterprise has been handicapped by the adjunctive, segregated, and marginal position. The exigencies of typography that moved graphics to a segregated position in the printed work have in the past contributed to their intellectual segregation and marginality as well”(Biderman, 1980).

Printed engineering textbooks and journals usually attempt to include referenced materials on the same spread as the reference. In printed engineering textbooks, the spreads (facing pages) are designed so that pertinent text, figures, and equations are in proximity and the reader can consider them simultaneously. While disappointing to Biderman, this approach has been the status quo for decades in engineering textbooks and journals.

Proximity in Printed Engineering Textbooks

A study was conducted to quantify the proximity of text, figures, equations, and tables in several current-edition printed textbooks used in civil engineering. Four textbooks were selected that are marketed for undergraduate steel design courses. The textbooks used for the study are listed in Table 1.

Table 1 Textbooks used for proximity study

\begin{tabular}{lll} 
Author(s) & Title & Length (pgs) \\
\hline William T. Segui & Steel Design (5 $5^{\text {th }}$ Edition) & 752 \\
Jack C. McCormac & Structural Steel Design (4th Edition) & 692 \\
Louis F. Geschwindner & Unified Design of Steel Structures & 444 \\
C. Salmon and J. Johnson & Steel Structures: Design and Behavior (4 ${ }^{\text {th }}$ Edition) & 1025 \\
\hline
\end{tabular}

In each book, three or more random samples were taken, altogether consisting of more than fifty pages. For the sampled pages, all of the references made in the text to figures, equations, tables, and examples were documented, as well as the proximity of the referenced items (same page, facing page, different spread). Results were compiled by book and altogether. 
Table 2 Average number of each type of reference per page

\begin{tabular}{lccccc} 
& \multicolumn{3}{c}{ References/Page } \\
Author(s) & Figures & Equations & Tables & Examples & Total \\
\hline William T. Segui & 0.71 & 0.30 & 0.10 & 0.05 & 1.16 \\
Jack C. McCormac & 0.71 & 0.08 & 0.07 & 0.15 & 1.01 \\
Louis F. Geschwindner & 1.18 & 0.38 & 0.16 & 0.08 & 1.80 \\
C. Salmon and J. Johnson & 1.12 & 0.18 & 0.06 & 0.00 & 1.36 \\
\hline All & 0.93 & 0.24 & 0.10 & 0.07 & 1.33 \\
\hline
\end{tabular}

Table 2 indicates the average number of each type of reference per page. While results vary for each book in all cases the number of references to figures was greater than the number of references to equations, tables, and examples combined. The fact that all the books covered material from the same discipline and were designed for the same audience probably explains the similarity in balance between references to figures and references of other kinds. Another observation is that the total number of references per page is not tremendous, ranging from 1.0 to 1.8 references per page with an average of 1.33 references per page.

The proximities of the objects being referenced are quantified in Table 3. For all of the books, between 33 to 50 percent of the references made in the text were to objects that could be found on the same page, and between 16 and 27 percent of the references were to objects that could be found on a facing page. On average, 63 percent of referenced objects were considered proximate (same spread), meaning that the object being referenced could easily be considered without leaving the spread. The results are remarkably consistent for Segui and McCormac, each with about 66 proximity; these two books have the greatest market share for undergraduate steel courses. Proximities in this neighborhood reflect the effort of publishers to keep referenced objects on the same spread.

Table 3 Proximities of referenced objects

\begin{tabular}{lcccc} 
& \multicolumn{4}{c}{ Proximity of Referenced Objects (\%) } \\
Author(s) & Same Page & Facing Page & Same Spread & Further \\
\hline William T. Segui & 50.0 & 15.6 & 65.6 & 34.4 \\
Jack C. McCormac & 50.0 & 16.7 & 66.7 & 27.7 \\
Louis F. Geschwindner & 33.3 & 15.6 & 48.9 & 50.0 \\
C. Salmon and J. Johnson & 45.5 & 26.7 & 72.2 & 27.7 \\
\hline All & 44.7 & 18.7 & 63.4 & 36.6 \\
\hline
\end{tabular}


Proximity in Current-Generation Engineering Digital Textbooks

The spread, which is the fundamental unit in modern textbook publishing, is disrupted by digital forms of printed textbooks. On notepad-sized devices, the PDF versions of a textbook are only viewed half-a-spread at a time at normal scale. Thus, even if a notepad-sized electronic device screen had infinite resolution it could still only present half as much material as an open book which has two pages shown at a time. Flowable-text versions of textbooks display even smaller fractions of a spread at a time and often alter the proximity of equations and figures such that accompanying text may not be considered simultaneously.

The data from Table 3 can be used to predict the loss of proximity for PDF versions of printed texts. When books are viewed one page at a time, rather than one spread at a time, the objects that lose proximity are those located on the facing pages. For the books considered, the average proximity drop would be 18.7 percent, so the average overall proximity of referenced objects would be only 44.7 percent (see Table 3 ).

Many printed textbooks are converted into standard e-book form with flowable text. In these etextbook versions, low resolution thumbnails of the figures are often embedded with text and can only be viewed in full resolution by tapping on the figure or by zooming in the figure such that it fills the screen. When the full resolution figure comes up, it replaces the text on the screen. This approach destroys the proximity of all the figures in the text! The figures cannot be considered simultaneously with the text that is describing them. For the four books in this study, figures account for the majority of the referenced objects. The loss of proximity in flowable text versions of engineering textbooks is more difficult to quantify, because treatment of figures vary. I estimate that digital textbooks with flowable text have overall proximity of less than 20 percent.

When the proximity of figures, equations, and tables in current-generation electronic textbooks is compared with the masterful integration of text and non-textual material in Leonardo da Vinci's notebooks, the difference is overwhelming. In some respects, we have not leveraged our technology to improve our communication of engineering concepts. 


\section{Potential Impact on Student Learning}

It is unclear if the loss of proximity in current-generation e-textbooks has a significant impact on student learning because there is little in the literature that is directly pertinent. A few indirectly related studies, that may give clues, are discussed next.

In a very limited study on a general science topic, Mayer et al. (1995) demonstrated that proximate illustrations with captions were significantly more effective in preparing students to correctly answer transfer problems than non-proximate illustrations. They also demonstrated, however, that the captions which annotated the illustrations explained the difference in student performance, rather than the proximity of the illustrations. This emphasizes the important of text (the caption) that accompanies the figures. In engineering textbooks, the discussion of figures may take up entire paragraphs and is not limited to a brief caption. It is unclear how the conclusions of this limited study apply to engineering textbooks without further research.

With regards to electronic mediums in general, some studies using psychology e-textbooks suggest that e-textbooks do not impact student learning relative to printed textbooks (Shepperd et al., 2008, Taylor, 2011). Daniel and Woody (2013) recently investigated students' use and performance on a variety of print and electronic formats in both laboratory and at home conditions. They randomly assigned students to use a chapter of an introductory psychology textbook in one of five formats: print textbook, printed text pages, printed manuscript in Microsoft Word, electronic pdf, or electronic textbook. The results from the study indicated that the various formats had no significant impact on student learning, although the electronic versions took students longer to read. If these results translate to engineering textbooks, they suggest that e-textbooks may not be detrimental, but perhaps only less efficient as learning tools. In real-world environments, where student time is limited, I believe that less efficient would also translate to less learning.

There is a need to better understand how figure proximity in engineering e-textbooks impacts student learning. Caution is warranted in a political and social environment where administrators are tempted to mandate e-textbooks. E-textbooks for engineering should not be mandated until research has demonstrated that they are equally effective (Daniel and Woody, 2013).

Potential Increases in Proximity

As implied in a previous section, even the proximity in printed textbooks is far from ideal. In the books studied, 36.6 percent of the references were to objects that were not proximate (see Table 3). 
Intelligent digital composition should be able to overcome this limitation. For example, a device screen could be divided into two windows - one with the text being read, and the other with referenced material. With high resolution note-pad devices, 100 percent proximity should be achievable. This type of next-generation e-textbook could improve proximity and potentially improve student learning as compared to printed textbooks. In planning research studies, it may be more useful to develop and test the effectiveness of next-generation e-textbooks with 100 percent proximity, rather than quantify how current-generation e-textbooks are less effective.

\section{Conclusions}

Political and social forces are pushing for the adoption of e-textbooks and their use is likely to increase in coming years. This paper has explored issues relating to proximity of text, figures, and equations in printed and e-textbooks. The primary purpose of the paper is to quantify proximity in typical printed civil engineering textbooks and quantify the loss of proximity in etextbook translations of these printed books.

In PDF versions of printed textbooks, the average loss in proximity is 19 percent. In flowable text versions the loss is greater, depending on how the figures are handled. It is unclear how these changes in proximity impact student learning. Studies in non-engineering disciplines have shown that it takes students longer to read textbooks in electronic forms and that it significantly impacts learning when figures are not adjacent to descriptive text.

Caution is warranted for those that are anxious to mandate e-textbooks. Further research is necessary to determine the effectiveness of engineering e-textbooks, especially because the loss of proximity suggests they may be inferior learning tools. 


\section{References}

Biderman, A. D. (1980). "The Graph as a Victim of Adverse Discrimination and Segregation." Information Design Journal, 1(4), 11.

Daniel, D. B., and Woody, W. D. (2013). "E-textbooks at What Cost? Performance and Use of Electronic v. Print Texts." Computers \& Education, 62(0), 18-23.

FRBNY (2012). "Quarterly Report on Household Debt and Credit." Quarterly Report on Household Debt and Credit, Federal Reserve Bank of New York (FRBNY).

GAO (2005). "College Textbooks: Enhanced Offerings Appear to Drive Recent Price Increases." United States Government Accountability Office, Washington D.C.

Garber, M. (2012). "California Takes a Big Step Forward: Free, Digital, Open-Source Textbooks." The Atlantic.

Jamrisko, M., and Kolet, L. (2012). "Cost of College Degree in US Soars 12 Fold: Chart of the Day." Bloomberg.com.

Mayer, R. E., Steinhoff, K., Bower, G., and Mars, R. (1995). "A Generative Theory of Textbook Design: Using Annotated Illustrations to Foster Meaningful Learning of Science Text." Educational Technology Research and Development, 43(1), 31-43.

Mishel, L., Bivens, J., Gould, E., and Shierholz, H. (2012). The State of Working America, Cornell University Press.

Shepperd, J. A., Grace, J. L., and Koch, E. J. (2008). "Evaluating the Electronic Textbook: Is It Time to Dispense With the Paper Text?" Teaching of Psychology, 35(1), 2-5.

Taylor, A. K. (2011). "Students Learn Equally Well From Digital as From Paperbound Texts." Teaching of Psychology, 38(4), 278-281.

Toppo, G. (2012). "Obama Wants Schools to Speed Digital Transition." USA Today.

Tufte, E. R. (1983). The Visual Display of Quantitative Information, Graphics Press, Cheshire, Connecticut.

Woody, W. D., Daniel, D. B., and Baker, C. A. (2010). "E-books or Textbooks: Students Prefer Textbooks." Computers \& Education, 55(3), 945-948.

Young, J. R. (2010). "To Save Students Money, Colleges May Force a Switch to E-textbooks." The Chronicle of Higher Education. 